\title{
Ethene Dimerization on Zeolite-Hosted Ni lons: Reversible Mobilization of the Active Site
}

\author{
Rasmus Yding Brogaard, ${ }^{*}, \dagger,+, I_{\odot}$ Mustafa Kømurcu, ${ }^{\dagger}$ Michael Martin Dyballa, ${ }^{\dagger}$ Alexandru Botan, ${ }^{\S}$ \\ Veronique Van Speybroeck, ${ }^{\ddagger}$ Unni Olsbye, ${ }^{*}+\odot$ and Kristof De Wispelaere ${ }^{*, *}$ \\ ${ }^{\dagger}$ Department of Chemistry, Centre for Materials and Nanoscience (SMN), University of Oslo, P.O. Box 1033, Blindern, NO-0315 \\ Oslo, Norway \\ ${ }^{\ddagger}$ Center for Molecular Modeling (CMM), Ghent University, Tech Lane Ghent Science Park Campus A, Technologiepark 46, 9052 \\ Zwijnaarde, Belgium \\ ${ }^{\S}$ Department of Physics, Centre for Materials and Nanoscience (SMN), University of Oslo, P.O. Box 1033, Blindern, NO-0315 \\ Oslo, Norway
}

\section{Supporting Information}

ABSTRACT: The active site in ethene oligomerization catalyzed by Ni-zeolites is proposed to be a mobile $\mathrm{Ni}$ (II) complex, based on density functional theory-based molecular dynamics (DFT-MD) simulations corroborated by continuous-flow experiments on Ni-SSZ-24 zeolite. The results of the simulations at operating conditions show that ethene molecules reversibly mobilize the active site as they exchange with the zeolite as ligands on $\mathrm{Ni}$ during reaction. Microkinetic modeling was conducted on the basis of free-energy profiles derived with DFT-MD for oligomerization on these mobile $\left[(\text { ethene })_{2}-\mathrm{Ni} \text {-alkyl }\right]^{+}$species. The model reproduces the experimentally observed high selectivity to dimerization and indicates that the mechanism is consistent with the observed second-order rate dependence on ethene pressure.
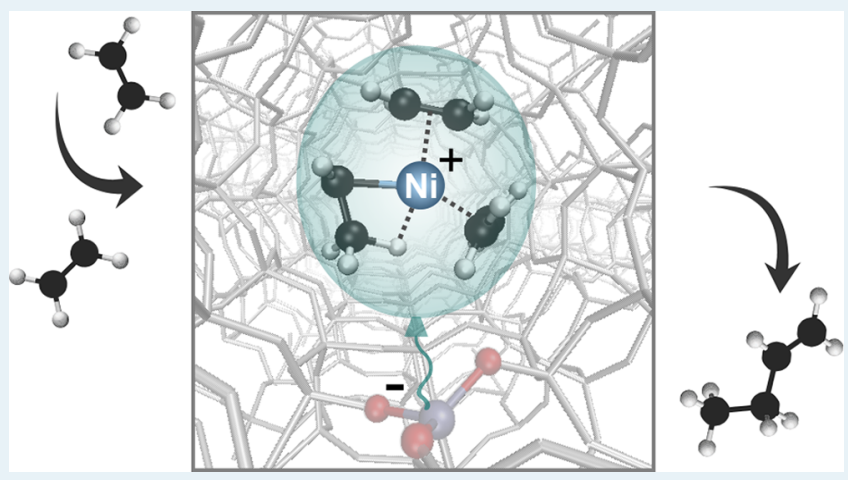

KEYWORDS: adsorption, host-guest systems, molecular dynamics, agostic interactions, alkene oligomerization, homogeneous catalysis

$\mathrm{H}$ omogeneous and heterogeneous catalysts are traditionally distinguished by the active site being either in solution or anchored on a support. However, recent works have revealed heterogeneous catalysts where the active sites are mobilized: selective catalytic reduction of nitrogen oxides with ammonia in Cu-SSZ-13 zeolite ${ }^{1}$ and with hydrocarbons in AgZSM-5 zeolite, ${ }^{2}$ reactant-mobilized protons in methanol to hydrocarbons conversion in $\mathrm{H}-\mathrm{ZSM}-5{ }^{3}$ and ethylene dimerization/hydrogenation on $\mathrm{Rh}$ sites in $\mathrm{Y}$ zeolite. ${ }^{4}$ In this work, we present findings on a reaction, ethene oligomerization in Ni-SSZ-24 zeolite, that indicate that the active site is reversibly mobilized and anchored to the support during the catalytic cycle.

There is increasing interest in selective oligomerization of alkenes, and in particular heterogeneous catalysts for ethene dimerization, as it is both a fundamentally challenging topic of catalysis and a versatile reaction for the chemical industry, such as forming butene from biobased ethylene. ${ }^{5} \mathrm{Ni}$-aluminosilicates have long been known as promising heterogeneous catalysts. ${ }^{6}$ Intriguingly, they work without the alkylaluminoxane cocatalysts required for homogeneous and metal-organic framework (MOF)-based heterogeneous catalysts. ${ }^{7}$ Never- theless, there is accumulating evidence provided by us and others that the reaction follows the Cossee-Arlman mechanism (Scheme 1$)^{8-11}$ known from homogeneous catalysis. The three-dimensional structure of the Ni-aluminosilicates plays a central role in alkene oligomerization: experimental results show that dimer formation is first order in alkene pressure on $\mathrm{Ni}$-silicaalumina ${ }^{10,12}$ but second order in Ni-zeolites. ${ }^{12,13} 1$ Butene formation is also second order in mesoporous $\mathrm{Ni}$ silicaalumina at low temperatures, where it was demonstrated that condensation of ethene in the pores stabilized catalytic activity. ${ }^{14}$ These observations suggest that surrounding molecules can have a significant influence on alkene oligomerization in Ni-aluminosilicates, an influence we for the first time elucidate with molecular simulations mimicking operating conditions.

We simulated ethene oligomerization in Ni-SSZ-24 using density-functional-theory-based molecular dynamics (DFTMD) simulations and advanced free-energy sampling techni-

Received: February 18, 2019

Revised: $\quad$ May 15, 2019

Published: May 22, 2019 
Scheme 1. Cossee-Arlman Catalytic Cycle of Ethene Oligomerization in $\mathrm{Ni}(\mathrm{II})$ Cationic Complexes

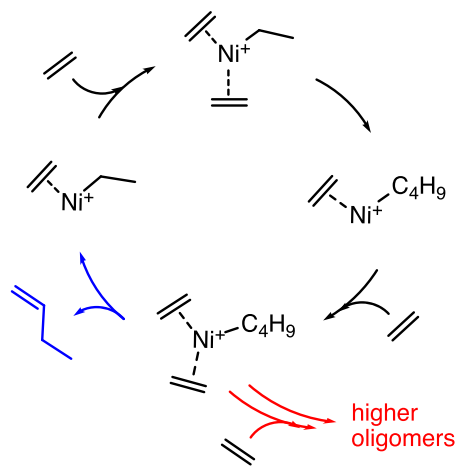

ques. Such an approach has proven to account for the complexity of catalytic reactions at operating conditions by allowing for dynamic active sites and the influence of surrounding molecules. ${ }^{3,15}$ The latter was found to be critical to investigate the nature of the active site in the presence of multiple ethene molecules. The computational results show a remarkable resemblance between the active sites in Ni-zeolites and homogeneous catalysts for alkene oligomerization, as ethene molecules reversibly mobilize the $\mathrm{Ni}$ site inside the zeolite pores. Continuous-flow experiments were conducted to verify the corresponding kinetic parameters predicted from theory. This leads us to predict that the active site within the Ni-zeolite dynamically crosses the border between homogeneous and heterogeneous catalysis throughout the reaction.

The computational part of this work takes its starting point in the Cossee-Arlman cycle, shown in Scheme 1, inferring that the Ni-ethyl species initially forms in situ by reaction between $\mathrm{Ni}(\mathrm{II})$ ions and ethene (Section S1). ${ }^{11}$ We seek to unravel the dynamics of the active site at operating conditions by simulating the catalytic cycle in Ni-SSZ-24 zeolite with DFTMD (see details in Computational and Experimental Methods), starting from the simplest Cossee-Arlman species [ethene-Ni-ethyl] $^{+}$surrounded by 2 ethene molecules in the micropore of the simulation cell (Section S2.2). This ethene loading corresponds to equilibrium at typical experimental conditions of $120{ }^{\circ} \mathrm{C}$ and 25 bar ethene pressure, ${ }^{10,12}$ as evidenced by Grand Canonical Monte Carlo simulations (Section S3). We have investigated several reaction steps and obtain good agreement in the free-energy barriers of the few of these steps that were investigated in our previous work (Section S2.4). ${ }^{8}$ We collected the free-energy profiles of the elementary steps that make up the most favorable pathways for ethene oligomerization in the diagram shown in Figure 1. Note that alkene adsorption/desorption in this diagram occurs from/to the zeolite pore encompassing the adsorbates. By using the equilibrium loading of two ethene molecules surrounding the [ethene-Ni-ethyl $]^{+}$species, we ensure that in this state the free energy of ethene in the pore is equivalent to that of gas phase ethene at $120^{\circ} \mathrm{C}$ and 25 bar.

Remarkably, the catalytic cycle of oligomerization proceeds on mobile complexes. Such a species is created from [ethene$\mathrm{Ni}$-ethyl $]^{+}$by coordination of an additional ethene to $\mathrm{Ni}$, thereby detaching the $\mathrm{Ni}$ complex from the ion-exchange position of the zeolite to create a mobile active site. The mobility is observed in the distribution of $\mathrm{Ni}-\mathrm{Al}$ distances in Figure 2: the distribution is shifted toward larger values and is wider for the detached $\left[(\text { ethene })_{2}-\mathrm{Ni} \text {-ethyl }\right]^{+}$than the anchored species. In the mobile species $\mathrm{Ni}$ can achieve its preferred square-planar coordination, realizing the maximal potential of the metal site by opening up a favorable pathway for $\mathrm{C}-\mathrm{C}$ coupling (vide infra). Figure 2 shows the simulated free-energy profiles for coordination of ethenes on $\mathrm{Ni}$-alkyl

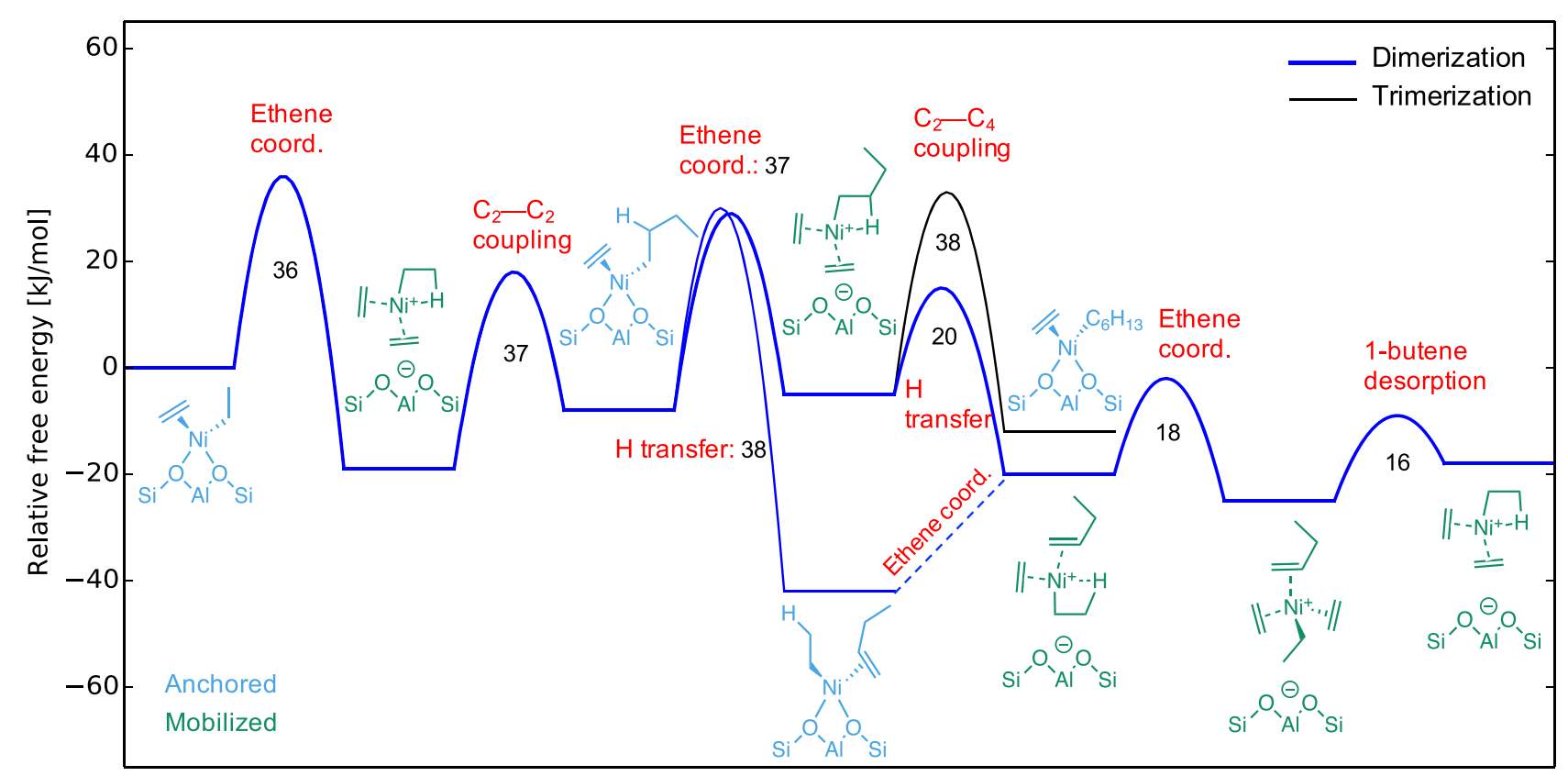

Reaction progress $\rightarrow$

Figure 1. Free-energy diagram for ethene oligomerization pathways in Ni-SSZ-24 zeolite at 25 bar and $120{ }^{\circ} \mathrm{C}$, based on free-energy profiles of elementary steps obtained with DFT-MD umbrella sampling simulations. The reference state is the equilibrium loading of ethene surrounding [ethene-Ni-ethyl] $]^{+}$, as discussed in the text. The numbers indicate intrinsic free energies of activation in $\mathrm{kJ} / \mathrm{mol}$. As indicated in the diagram, the [ethyl-Ni-butene $]^{+}$species can also be reached by ethene desorption; see Section S2.3 for a detailed discussion of how the diagram was constructed. 

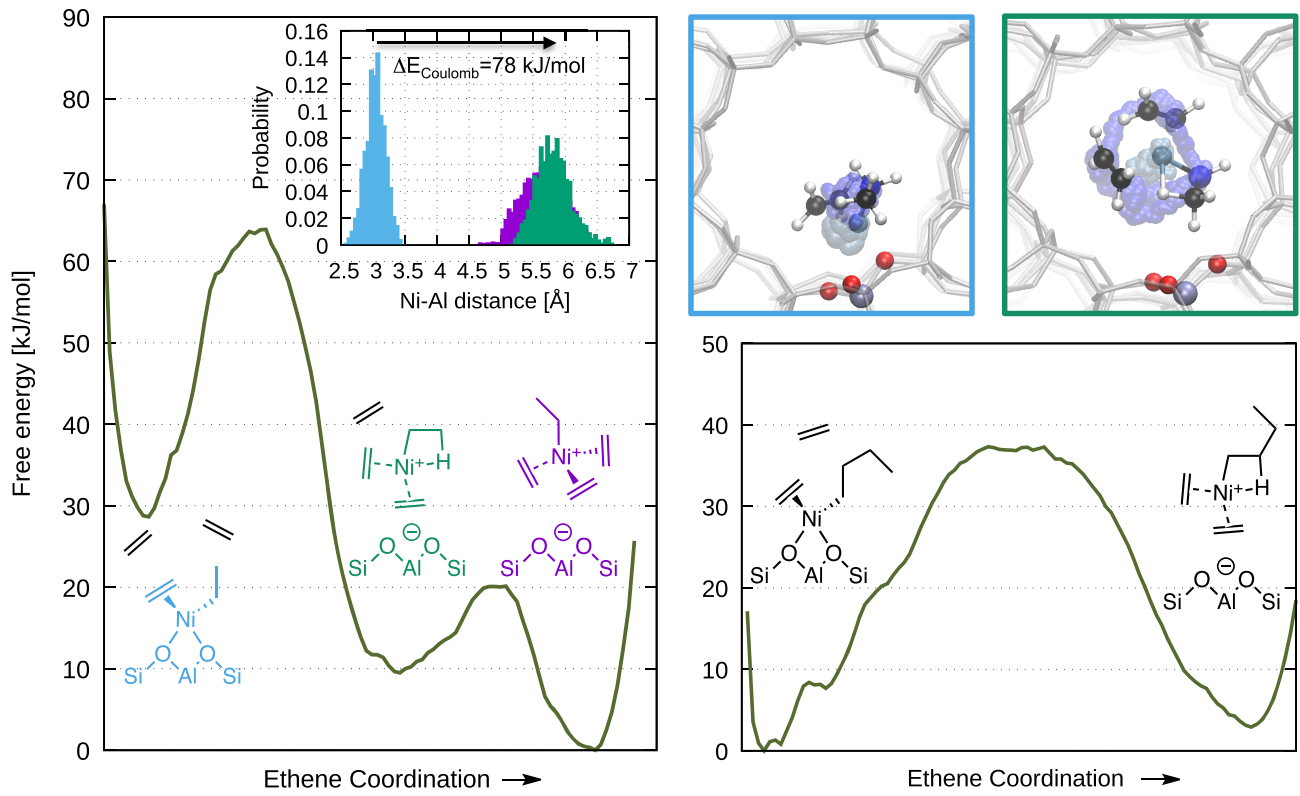

Figure 2. Free-energy profiles for ethene coordination to [ethene-Ni-ethyl $]^{+}$(left) and [ethene-Ni-butyl $]^{+}$(right) at 25 bar and $120{ }^{\circ} \mathrm{C}$, derived from DFT-MD simulations. The left inset shows histograms of Ni-Al distances, illustrating that the doubly and triply ethene-coordinated Ni-ethyl species are detached from the framework and more mobile than their anchored counterpart. The associated charge-separation energy is estimated to $78 \mathrm{~kJ} / \mathrm{mol}$ (Section S2.5). The right insets show snapshots from the simulations of the Ni-ethyl species, including the trajectories of the Ni (light blue) and the $\alpha$ alkyl C (dark blue) atoms (Figure S8 shows the butyl analogues).

Table 1. Intrinsic Free-Energy Barriers $(\mathrm{kJ} / \mathrm{mol})$ of Ethene Desorption and C-C Coupling in $\left[(\text { ethene })_{x} \text {-Ni-ethyl }\right]^{+}$Species in SSZ-24 Zeolite, Obtained from DFT-MD Simulations at $120^{\circ} \mathrm{C}$ (Sections S2.7 and S2.8)

$\begin{array}{lccc} & {\text { [ethene-Ni-ethyl }]^{+}} & {\left[(\text {ethene })_{2} \text {-Ni-ethyl }\right]^{+}} & {\left[(\text {ethene })_{3} \text {-Ni-ethyl }\right]^{+}} \\ \mathrm{C}-\mathrm{C} \text { coupling } & 77 & 37 & 76 \\ \text { ethene desorption } & 72 & 54 & 20\end{array}$

species originally anchored to the zeolite. The results show that $[\text { ethene-Ni-ethyl }]^{+}$is stabilized by coordination of up to two additional ethene molecules. In $[\text { (ethene })_{2}$-Ni-ethyl $]^{+}$, one oxygen coordination is replaced by ethene and the second by an agostic bond with a $\beta$ hydrogen of the ethyl group, creating a square planar coordination of $\mathrm{Ni}$ (Figure 2, right inset). The same is the case for the butyl analogue (Figure S8). This square-planar geometry is preferred for $\mathrm{Ni}$ as a $\mathrm{d}^{8}$ metal when coordinated to strong-field ligands, ${ }^{16}$ such as alkyl and hydride. ${ }^{17}$

The mobile $\mathrm{Ni}$ complexes resemble a homogeneous oligomerization catalyst in solution; the noncovalent interactions with the zeolite framework parallel the nondirectional stabilization by a solvent shell. However, the positively charged complex is tethered to the zeolite framework by the negative charge of the ion-exchange site. Note that there is a potential energy gain on formation of the $\left[(\text { ethene })_{2} \text {-Ni-ethyl }\right]^{+}$ detached species $(28 \mathrm{~kJ} / \mathrm{mol}$, Section S2.6.1). Ethene coordination thus counteracts the energy required to separate the positive $\mathrm{Ni}$ ion from the framework $(78 \mathrm{~kJ} / \mathrm{mol}$, Figure 2). As complex formation is also favored in free energy $(19 \mathrm{~kJ} /$ mol, Figure 2), the entropy loss of coordinating ethene is partly compensated by the configurational entropy of the mobile $\left[(\text { ethene })_{2}-\mathrm{Ni} \text {-ethyl }\right]^{+}$complex; translation (Figure S9) and rotation (inset of Figure 2). This rotation may also explain why ethene coordination to [ethene-Ni-butyl $]^{+}$is favored in potential energy $(38 \mathrm{~kJ} / \mathrm{mol}$, Section S2.6.1) but slightly disfavored in free energy $(3 \mathrm{~kJ} / \mathrm{mol}$, Figure 2$)$; the Ni-butyl species is bulkier than the ethyl analogue, limiting rotation in the zeolite micropore (Figure S8).

$\mathrm{C}-\mathrm{C}$ coupling is the central reaction step in ethene oligomerization, which in the mobile species proceeds through migratory insertion of ethene in the Ni-alkyl bond. We find the intrinsic free-energy barrier in $[\text { (ethene })_{2}-\mathrm{Ni}$-ethyl $]^{+}$to be significantly lower than in both the anchored [ethene-Niethyl $]^{+}$species and the mobile $\left[(\text {ethene })_{3} \text {-Ni-ethyl }\right]^{+}$species (Table 1). We explain this trend using Hammond's postulate ${ }^{18}$ considering the structures shown in Figure 3; $\mathrm{C}-\mathrm{C}$ coupling in [ethene-Ni-ethyl] $^{+}$is an endergonic reaction (Figure S11) leading to a large activation barrier with a late transition state that resembles a $[\mathrm{Ni} \text {-butyl }]^{+}$product with a $\gamma$-agostic hydrogen bond. In $[\text { (ethene })_{2}$-Ni-ethyl $]^{+}$, the reaction is exergonic (Figure S13), leading to a low activation barrier with an early transition state that resembles the reactant with the favorable square-planar coordination of $\mathrm{Ni}$. In [(ethene $)_{3}$-Niethyl $]^{+}$the transition state (trigonal bipyramid) resembles neither the reactant (half trigonal bipyramid) nor the product ([(ethene $)_{2}$-Ni-butyl $]^{+}$, square planar) and is hence significantly higher in free energy than either state (Figure S14). The Ni-butyl analogues exhibit the same trend (Figures S11 and S13).

Following $\mathrm{C}-\mathrm{C}$ coupling, the reaction proceeds from $\left[(\text { ethene })_{2} \text {-Ni-butyl }\right]^{+}$via transfer of a $\beta$ hydrogen of the butyl chain to form 1-butene, which subsequently desorbs. Like for $\mathrm{C}-\mathrm{C}$ coupling, the hydrogen transfer has the lowest barrier in the mobile $\left[(\text { ethene })_{2}-\mathrm{Ni} \text {-butyl }\right]^{+}$species $(20 \mathrm{~kJ} / \mathrm{mol}$, Figures 1 and S21), as hydrogen is already involved in an 

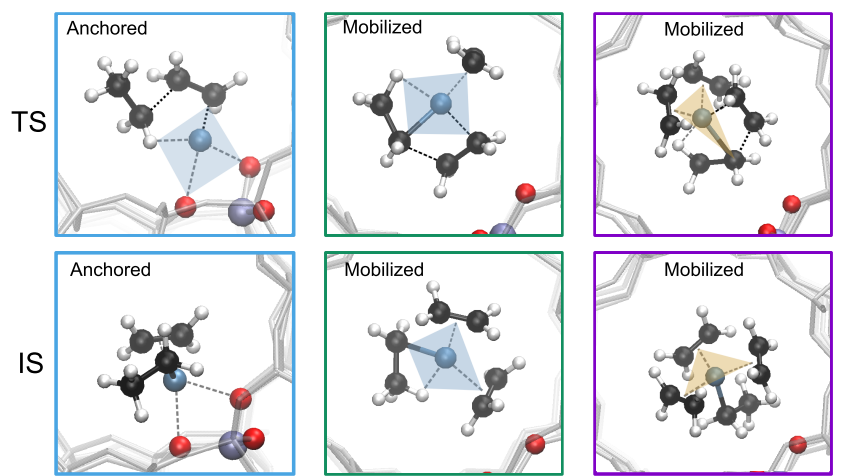

[ethene-Ni-ethyl] ${ }^{+}$

$\left[(\text { ethene })_{2}-\mathrm{Ni} \text {-ethyl }\right]^{+}\left[(\text {ethene })_{3}-\mathrm{Ni} \text {-ethyl }\right]^{+}$

Figure 3. Snapshots from DFT-MD umbrella simulations of the initial (IS) and transition states (TS) of C-C coupling in [(ethene) $)_{x}$-Niethyl $]^{+}$species in SSZ-24 zeolite. Planes of square and trigonal coordination are shown in blue and yellow, respectively.

agostic bond to Ni prior to reaction (see Ni-ethyl analogue in Figure 3). In contrast, the anchored [ethene-Ni-butyl] ${ }^{+}$species undergoes a significant rearrangement to reach the transition state, reflected in a higher barrier $(38 \mathrm{~kJ} / \mathrm{mol}$, Figures 1 and S18).

The last step toward dimerization is desorption of 1-butene. Analogously to ethene (Table 1), the 1-butene desorption barrier decreases with ethene coordination and is hence lowest in $\left[(\text { ethene })_{2} \text {-ethyl-Ni-1-butene }\right]^{+}($Table S5). This can be explained by the late transition state of desorption: in this species, the 1-butene weakly interacts with the favored squareplanar [(ethene $)_{2}$-Ni-ethyl $]^{+}$(Figure S22). In the latter species, the catalytic cycle is closed.

In summary, we have used DFT-MD to predict that both ethene dimerization and trimerization are catalyzed by positively charged $\mathrm{Ni}$ complexes mobilized by ethene coordination. The transition states involved in butene formation are slightly lower in free energy than that for hexene formation (Figure 1), indicating a preference toward butene over higher oligomers. Indeed, when employing the free-energy profiles in a microkinetic model (Section S4), we obtain a rate of formation of 1-butene that is 2 orders of magnitude higher than that of 1-hexene (Section S4.3).

We now consider experimental results to verify our computational findings. Ethene oligomerization was investigated in continuous-flow experiments on Ni-SSZ-24 zeolite (see details in Computational and Experimental Methods). The catalyst achieves a selectivity of more than $98 \%$ to butenes at ethene pressures ranging from 4 to 26 bar (Section S5.3), in agreement with the computational result that the production rate of butene is 2 orders of magnitude higher than that of hexene as a representative of higher oligomers. Figure 4 shows that the rate of butene (and hexene) formation is second order in ethene pressure and that the apparent activation energy is virtually pressure-independent. These findings strongly suggest that the oligomerization mechanism is the same over a wide pressure range. The observed reaction order agrees with microkinetic modeling based on the free-energy profiles shown in Figure 1, where oligomerization occurs on mobile active sites. Note that a second order is only obtained from the model when [ethyl-Ni-alkene] ${ }^{+}$species are the most abundant adsorbates, the catalyst resting states (Table S7, Section S4.3). We note that the predicted coverage of [ethyl-Nialkene $]^{+}$and hence the reaction order is sensitive to the free
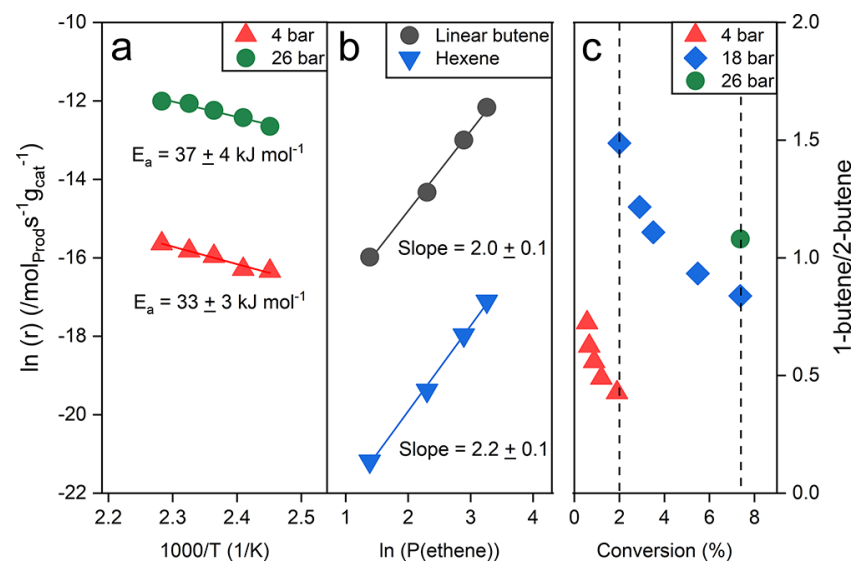

Figure 4. Results from continuous-flow experiments on ethene oligomerization in Ni-SSZ-24: (a) Arrhenius plot for butene formation at 4 and 26 bar ethene pressure, (b) reaction order of butene and hexene formation at $150{ }^{\circ} \mathrm{C}$, and (c) butene isomer selectivity at $150{ }^{\circ} \mathrm{C}$. All results were obtained at differential ethene conversions of $1-7 \%$.

energy of these species (Table S7), which is associated with some uncertainty (Section S2.3). However, a zeolite-anchored [ethyl-Ni-alkene] ${ }^{+}$resting state is consistent with recent experimental X-ray absorption data, which indicate that in the catalyst resting state in Ni-Beta zeolite, $\mathrm{Ni}$ is in tetrahedral coordination with oxygens in the first coordination shell. ${ }^{11}$ In the context of resting states it is instructive to consider the concept of the energetic span introduced by Kozuch and Shaik: the largest free-energy difference between an adsorbate and a transition state along the catalytic cycle, corresponding to the apparent free energy of activation. ${ }^{19}$ While being cautious about using the free energies from Figure 1 directly (Section S2.3), we derive an energetic span for butene formation of 71 $\mathrm{kJ} / \mathrm{mol}$ between the [ethyl-Ni-butene ${ }^{+}$and the transition state of hydrogen transfer, which is in fairly good agreement with the $58 \mathrm{~kJ} / \mathrm{mol}$ derived from the experiments (Section S5.3.1).

Finally, the experimental results indicate that both 1- and 2butenes are primary products (Section S5.3), as was also observed on Ni-Beta. ${ }^{1}$ This supports the Cossee-Arlman mechanism, as the [ethyl-Ni-butene] ${ }^{+}$species can isomerize between 1- and 2-butene through $\beta$-hydrogen elimination on the Ni site prior to desorption (Figure S17), analogously to homogeneous catalysts. ${ }^{20}$ Note also that 1-butene selectivity increases with pressure (Figure 4), contrary to what would be expected for isomerization at Brønsted acid sites, but paralleling the results of previous work by Agirrezabal-Telleria and Iglesia on mesoporous Ni-silicaalumina. ${ }^{14}$ Interestingly, the same work demonstrated stabilization of catalytic activity at subambient temperatures when ethene condenses in the mesopores. ${ }^{14}$ Such conditions likely favor coordination of multiple ethene molecules to form the mobile sites described here (Section S6). These sites may be involved in the stabilization, as they facilitate butene desorption over further oligomerization.

In conclusion, we have conducted an experimental and computational investigation of ethene oligomerization in $\mathrm{Ni}$ SSZ-24 zeolite. The computational results allow us to make detailed predictions about the reaction at operating conditions; two ethene molecules adsorb on Ni-alkyl species, creating mobile active sites in the zeolite pores. The mobilization is reversible, as ethene dynamically exchanges with oxygens of 
the zeolite support as ligand on $\mathrm{Ni}$ during the reaction. Microkinetic modeling based on calculated free-energy profiles reproduces the experimentally observed relative production rate of butene over higher oligomers of $10^{2}$. The model indicates that the proposed mechanism leads to a second-order rate dependence on ethene pressure as experimentally observed here and elsewhere. ${ }^{12,14}$ An analogous mechanism may explain the second-order rate dependence observed in 1butene dimerization. ${ }^{13}$ Such reactant-mobilized active sites have also been observed in selective catalytic reduction of nitrogen oxides with ammonia in Cu-SSZ-13 zeolite ${ }^{1}$ and with hydrocarbons in Ag-ZSM-5, ${ }^{2}$ in methanol to hydrocarbons conversion in $\mathrm{H}-\mathrm{ZSM}-5,{ }^{3}$ and ethylene dimerization/hydrogenation on $\mathrm{Rh}$ sites in $\mathrm{Y}$ zeolite. ${ }^{4}$ Together these works present materials that appear as hybrids between heterogeneous and homogeneous catalysts, highlighting an intriguing regime of catalysis ${ }^{21}$ that likely extends beyond the examples known to date.

\section{COMPUTATIONAL AND EXPERIMENTAL METHODS}

Density functional theory (DFT)-based Molecular Dynamics (DFT-MD) simulations were carried out with CP2K, ${ }^{22}$ versions 2.6 and 3.0. ${ }^{23}$ Energies and forces were calculated from DFT based on a mixed Gaussian and plane wave approach $^{24}$ using the revPBE functional ${ }^{25}$ with Grimme D3 dispersion correction. ${ }^{26}$ DFT-MD calculations were carried out nonspinpolarized, as our previous work determined the singlet state to be the most stable for the $\mathrm{Ni}$ (II) species investigated here. ${ }^{8}$ The majority of the simulations employed a super cell constructed by repeating the AFI unit cell twice along the channel direction $(1 \times 1 \times 2)$ and making one $\mathrm{Si} / \mathrm{Al}$ substitution $(\mathrm{Si} / \mathrm{Al}=47)$, while a larger super cell $(\mathrm{Si} / \mathrm{Al}=72)$ was used in a few simulations (Figure S23). Enhanced freeenergy sampling in the DFT-MD simulations was done using umbrella sampling ${ }^{27,28}$ with quadratic potentials by interfacing CP2K with PLUMED 2. ${ }^{29}$ Free-energy profiles of elementary reaction steps were computed from the output of umbrella simulations along collective variables, using the Weighted Histogram Analysis Method (WHAM). ${ }^{27}$ Monte Carlo simulations were carried out using LAMMPS, ${ }^{30}$ while microkinetic modeling was conducted with CatMAP. ${ }^{31}$ Graphics of molecular structures from the DFT-MD simulations were created using POV-Ray 3.6 and VMD 1.9.1. ${ }^{32}$

The synthesis of SSZ-24 was conducted as described in literature. $^{33}$ The zeolite was ion-exchanged five consecutive times with $0.1 \mathrm{M} \mathrm{Ni}\left(\mathrm{NO}_{3}\right)_{2}(\mathrm{aq})$, washed and calcined to form $\mathrm{Ni}-\mathrm{SSZ}-24, \mathrm{Si} / \mathrm{Al}=80, \mathrm{Ni} / \mathrm{Al}=0.34$. Kinetic experiments were carried out in a continuous-flow, fixed-bed, stainless steel reactor. Standard measurement conditions were $150{ }^{\circ} \mathrm{C}$ and 30 bar total pressure, $\mathrm{P}$ (ethene $)=26$ bar, $\mathrm{P}($ inert $)=4$ bar, with a total flow rate of $30 \mathrm{~mL} / \mathrm{min}$ (contact time at STP: $6.7 \mathrm{mg}_{\text {cat }}$. $\mathrm{min} \cdot \mathrm{mL}_{\text {ethene }}^{-1}$ ). A small fraction of the effluent was analyzed on an online gas chromatograph. Carbon mass balances closed witin $2 \%$. Further computational and experimental details can be found in the Supporting Information.

\section{ASSOCIATED CONTENT}

\section{S Supporting Information}

The Supporting Information is available free of charge on the ACS Publications website at DOI: 10.1021/acscatal.9b00721.
Complete body of DFT-MD results, results of Monte Carlo simulations, setup and results of microkinetic modeling, additional experimental details and results (PDF)

CatMAP files (ZIP)

\section{AUTHOR INFORMATION}

\section{Corresponding Authors}

*E-mail: rabr@topsoe.com.

*E-mail: unni.olsbye@kjemi.uio.no.

*E-mail: kristof.dewispelaere@ugent.be.

ORCID

Rasmus Yding Brogaard: 0000-0001-7882-9183

Michael Martin Dyballa: 0000-0002-8883-1145

Veronique Van Speybroeck: 0000-0003-2206-178X

Unni Olsbye: 0000-0003-3693-2857

\section{Present Address}

${ }^{\mathrm{T}}$ R.Y.B.: Haldor Topsøe A/S, Nymøllevej 55, DK-2800 Kgs. Lyngby, Denmark

\section{Notes}

The authors declare no competing financial interest.

\section{ACKNOWLEDGMENTS}

This research was funded in part by the Research Council of Norway through the OLIGOM (224980) and CONFINE (250795) projects. R.Y.B. thanks the University of Oslo for the Young Scientist Mobility Grant. V.V.S. and R.Y.B acknowledge funding from the European Union's Horizon 2020 research and innovation program (consolidator ERC grant agreement No. 647755 - DYNPOR (2015-2020)). The work is also supported by the Research Board of Ghent University (BOF). The Norwegian Metacenter for High Performance Computing (NOTUR) and Prof. Stian Svelle are thanked for computing resources (nn4683k). Ghent University (Stevin Supercomputer Infrastructure) and the VSC (Flemish Supercomputer Center), funded by the Research Foundation Flanders (FWO), are also thanked for computational resources. K.D.W. is a fellow funded by the FWO (FWO16-PDO-047).

\section{REFERENCES}

(1) Paolucci, C.; Khurana, I.; Parekh, A. A.; Li, S.; Shih, A. J.; Li, H.; Di Iorio, J. R.; Albarracin-Caballero, J. D.; Yezerets, A.; Miller, J. T.; Delgass, W. N.; Ribeiro, F. H.; Schneider, W. F.; Gounder, R. Dynamic Multinuclear Sites Formed by Mobilized Copper Ions in $\mathrm{NO}_{x}$ Selective Catalytic Reduction. Science 2017, 357, 898-903.

(2) Shibata, J.; Shimizu, K.-i.; Takada, Y.; Shichi, A.; Yoshida, H.; Satokawa, S.; Satsuma, A.; Hattori, T. Structure of Active Ag Clusters in Ag Zeolites for SCR of NO by Propane in the Presence of Hydrogen. J. Catal. 2004, 227, 367-374.

(3) Moors, S. L. C.; De Wispelaere, K.; Van der Mynsbrugge, J.; Waroquier, M.; Van Speybroeck, V. Molecular Dynamics Kinetic Study on the Zeolite-Catalyzed Benzene Methylation in ZSM-5. ACS Catal. 2013, 3, 2556-2567.

(4) Serna, P.; Gates, B. C. Zeolite-Supported Rhodium Complexes and Clusters: Switching Catalytic Selectivity by Controlling Structures of Essentially Molecular Species. J. Am. Chem. Soc. 2011, 133, 47144717.

(5) (a) Hulea, V. Toward Platform Chemicals from Bio-Based Ethylene: Heterogeneous Catalysts and Processes. ACS Catal. 2018, 8, 3263-3279. (b) Nicholas, C. P. Applications of Light Olefin Oligomerization to the Production of Fuels and Chemicals. Appl. Catal., A 2017, 543, 82-97. 
(6) Finiels, A.; Fajula, F.; Hulea, V. Nickel-based Solid Catalysts for Ethylene Oligomerization - a Review. Catal. Sci. Technol. 2014, 4, $2412-2426$

(7) (a) Canivet, J.; Aguado, S.; Schuurman, Y.; Farrusseng, D. MOFSupported Selective Ethylene Dimerization Single-Site Catalysts Through One-Pot Postsynthetic Modification. J. Am. Chem. Soc. 2013, 135, 4195-4198. (b) Madrahimov, S. T.; Gallagher, J. R.; Zhang, G.; Meinhart, Z.; Garibay, S. J.; Delferro, M.; Miller, J. T.; Farha, O. K.; Hupp, J. T.; Nguyen, S. T. Gas-Phase Dimerization of Ethylene under Mild Conditions Catalyzed by MOF Materials Containing (bpy) $\mathrm{Ni}^{\mathrm{II}}$ Complexes. ACS Catal. 2015, 5, 6713-6718. (c) Bernales, V.; League, A. B.; Li, Z.; Schweitzer, N. M.; Peters, A. W.; Carlson, R. K.; Hupp, J. T.; Cramer, C. J.; Farha, O. K.; Gagliardi, L. Computationally Guided Discovery of a Catalytic CobaltDecorated Metal-Organic Framework for Ethylene Dimerization. J. Phys. Chem. C 2016, 120, 23576-23583. (d) Metzger, E. D.; Comito, R. J.; Hendon, C. H.; Dincă, M. Mechanism of Single-Site MoleculeLike Catalytic Ethylene Dimerization in Ni-MFU-4l. J. Am. Chem. Soc. 2017, 139, 757-762. (e) Liu, J.; Ye, J.; Li, Z.; Otake, K.-i.; Liao, Y.; Peters, A. W.; Noh, H.; Truhlar, D. G.; Gagliardi, L.; Cramer, C. J.; Farha, O. K.; Hupp, J. T. Beyond the Active Site: Tuning the Activity and Selectivity of a Metal-Organic Framework-Supported Ni Catalyst for Ethylene Dimerization. J. Am. Chem. Soc. 2018, 140, 1117411178.

(8) Brogaard, R. Y.; Olsbye, U. Ethene Oligomerization in Nicontaining Zeolites: Theoretical Discrimination of Reaction Mechanisms. ACS Catal. 2016, 6, 1205-1214.

(9) Forget, S.; Olivier-Bourbigou, H.; Delcroix, D. Homogeneous and Heterogeneous Nickel-Catalyzed Olefin Oligomerization: Experimental Investigation for a Common Mechanistic Proposition and Catalyst Optimization. ChemCatChem 2017, 9, 2408-2417.

(10) Toch, K.; Thybaut, J.; Marin, G. Ethene Oligomerization on $\mathrm{Ni}-\mathrm{SiO}_{2}-\mathrm{Al}_{2} \mathrm{O}_{3}$ : Experimental Investigation and Single-Event MicroKinetic Modeling. Appl. Catal., A 2015, 489, 292-304.

(11) Joshi, R.; Zhang, G.; Miller, J. T.; Gounder, R. Evidence for the Coordination-Insertion Mechanism of Ethene Dimerization at Nickel Cations Exchanged onto Beta Molecular Sieves. ACS Catal. 2018, 8, 11407-11422.

(12) Henry, R.; Komurcu, M.; Ganjkhanlou, Y.; Brogaard, R. Y.; Lu, L.; Jens, K.-J.; Berlier, G.; Olsbye, U. Ethene Oligomerization on Nickel Microporous and Mesoporous-Supported Catalysts: Investigation of the Active Sites. Catal. Today 2018, 299, 154-163.

(13) Ehrmaier, A.; Liu, Y.; Peitz, S.; Jentys, A.; Chin, Y.-H. C.; Sanchez-Sanchez, M.; Bermejo-Deval, R.; Lercher, J. Dimerization of Linear Butenes on Zeolite-Supported $\mathrm{Ni}^{2+}$. ACS Catal. 2019, 9, 315324.

(14) Agirrezabal-Telleria, I.; Iglesia, E. Stabilization of Active, Selective, and Regenerable Ni-based Dimerization Catalysts by Condensation of Ethene within Ordered Mesopores. J. Catal. 2017, $352,505-514$.

(15) (a) Van Speybroeck, V.; De Wispelaere, K.; Van der Mynsbrugge, J.; Vandichel, M.; Hemelsoet, K.; Waroquier, M. First Principle Chemical Kinetics in Zeolites: the Methanol-to-Olefin Process as a Case Study. Chem. Soc. Rev. 2014, 43, 7326-7357. (b) De Wispelaere, K.; Ensing, B.; Ghysels, A.; Meijer, E. J.; Van Speybroeck, V. Complex Reaction Environments and Competing Reaction Mechanisms in Zeolite Catalysis: Insights from Advanced Molecular Dynamics. Chem. - Eur. J. 2015, 21, 9385-9396. (c) De Wispelaere, K.; Wondergem, C. S.; Ensing, B.; Hemelsoet, K.; Meijer, E. J.; Weckhuysen, B. M.; Van Speybroeck, V.; Ruiz-Martínez, J. Insight into the Effect of Water on the Methanol-to-Olefins Conversion in H-SAPO-34 from Molecular Simulations and in Situ Microspectroscopy. ACS Catal. 2016, 6, 1991-2002. (d) De Wispelaere, K.; Vanduyfhuys, L.; Van Speybroeck, V. Modelling and Simulation in the Science of Micro- and Meso-Porous Materials; Elsevier, 2017; Chapter entitled Entropy Contributions to Transition State Modelling. (e) Li, G.; Pidko, E. A. The Nature and Catalytic Function of Cation Sites in Zeolites: a Computational Perspective. ChemCatChem 2019, 11, 134-156.
(16) Gray, H. B.; Ballhausen, C. J. A Molecular Orbital Theory for Square Planar Metal Complexes. J. Am. Chem. Soc. 1963, 85, 260265.

(17) Chatt, J.; Hayter, R. G. 167. Ligand Field Strengths of the Halide, Methyl, Phenyl, and Hydride Anions. J. Chem. Soc. 1961, $772-774$.

(18) Hammond, G. S. A. Correlation of Reaction Rates. J. Am. Chem. Soc. 1955, 77, 334-338.

(19) Kozuch, S.; Shaik, S. How to Conceptualize Catalytic Cycles? The Energetic Span Model. Acc. Chem. Res. 2011, 44, 101-110.

(20) Ittel, S. D.; Johnson, L. K.; Brookhart, M. Late-Metal Catalysts for Ethylene Homo- and Copolymerization. Chem. Rev. 2000, 100, 1169-1204.

(21) Shamzhy, M.; Opanasenko, M.; Concepción, P.; Martínez, A. New Trends in Tailoring Active Sites in Zeolite-Based Catalysts. Chem. Soc. Rev. 2019, 48, 1095-1149.

(22) Hutter, J.; Iannuzzi, M.; Schiffmann, F.; VandeVondele, J. CP2K: Atomistic Simulations of Condensed Matter Systems. WIREs Comput. Mol. Sci. 2014, 4, 15-25.

(23) $\mathrm{CP} 2 \mathrm{~K}$, version 3.0 or higher, the $\mathrm{CP} 2 \mathrm{~K}$ developers group. CP2K is freely available from http://www.cp2k.org.

(24) VandeVondele, J.; Krack, M.; Mohamed, F.; Parrinello, M.; Chassaing, T.; Hutter, J. Quickstep: Fast and Accurate Density Functional Calculations using a Mixed Gaussian and Plane Waves Approach. Comput. Phys. Commun. 2005, 167, 103-128.

(25) (a) Perdew, J. P.; Burke, K.; Ernzerhof, M. Generalized Gradient Approximation Made Simple. Phys. Rev. Lett. 1996, 77, 3865-3868. (b) Zhang, Y.; Yang, W. Comment on "Generalized Gradient Approximation Made Simple. Phys. Rev. Lett. 1998, 80, 890-890.

(26) (a) Grimme, S.; Antony, J.; Ehrlich, S.; Krieg, H. A Consistent and Accurate $\mathrm{Ab}$ Initio Parametrization of Density Functional Dispersion Correction (DFT-D) for the 94 Elements H-Pu. J. Chem. Phys. 2010, 132, 154104. (b) Grimme, S.; Ehrlich, S.; Goerigk, L. Effect of the Damping Function in Dispersion Corrected Density Functional Theory. J. Comput. Chem. 2011, 32, 1456-1465.

(27) Kumar, S.; Rosenberg, J. M.; Bouzida, D.; Swendsen, R. H.; Kollman, P. A. The Weighted Histogram Analysis Method for Freeenergy Calculations on Biomolecules. I. The method. J. Comput. Chem. 1992, 13, 1011-1021.

(28) Ensing, B.; Laio, A.; Parrinello, M.; Klein, M. L. A Recipe for the Computation of the Free Energy Barrier and the Lowest Free Energy Path of Concerted Reactions. J. Phys. Chem. B 2005, 109, 6676-6687.

(29) Tribello, G. A.; Bonomi, M.; Branduardi, D.; Camilloni, C.; Bussi, G. PLUMED 2: New Feathers for an Old Bird. Comput. Phys. Commun. 2014, 185, 604-613.

(30) Plimpton, S. Fast Parallel Algorithms for Short-Range Molecular Dynamics. J. Comput. Phys. 1995, 117, 1-19.

(31) Medford, A. J.; Shi, C.; Hoffmann, M. J.; Lausche, A. C.; Fitzgibbon, S. R.; Bligaard, T.; Nørskov, J. K. CatMAP: A Software Package for Descriptor-Based Microkinetic Mapping of Catalytic Trends. Catal. Lett. 2015, 145, 794-807.

(32) Humphrey, W.; Dalke, A.; Schulten, K. VMD - Visual Molecular Dynamics. J. Mol. Graphics 1996, 14, 33-38.

(33) Kubota, Y.; Maekawa, H.; Miyata, S.; Tatsumi, T.; Sugi, Y. Hydrothermal Synthesis of Metallosilicate SSZ-24 from Metallosilicate Beta as Precursors. Microporous Mesoporous Mater. 2007, $101,115-126$. 